\title{
Pola Interaksi Sosial Anggota Subak Hindu dan NonHindu di Subak Pemaket Awen Selatan Desa Pengambengan, Kecamatan Negara, Kabupaten Jembrana
}

\author{
I WAYAN NIKA ASTIAWAN, I KETUT SURYA DIARTA, I MADE SARJANA
}

Program Studi Agribisnis, Fakultas Pertanian, Universitas Udayana

JL. PB. Sudirman Denpasar 80323

Email: nikastiawan@gmail.com

suryadiarta@yahoo.com

\begin{abstract}
Pattern Of Interaction Social In Members Of Hindu And Non Hindu In Subak Pemaket Awen Selatan Pengambengan Village Negara Subdistrict Jembrana Regency
\end{abstract}

Subak is a customary law community that has socio-agrarian-religious-economic characteristics, Subakof Pemaket Awen Selatan is one of subaks in Bali which has members of Hindu and Non Hindu. Religious differences embraced by members of Subak Pamekat Awen Selatan have led to the potential for conflict. This study was located in Subak Pembaket Awen Selatan, Pengambengan Village, Sub-District of Negara, Jembrana District. The study was conducted from January to March 2017. The data collection used snowball sampling method, that is by determining the number of samples of each religion that consisted of 15 people. Method of analyzing data used descriptive qualitative method. The results showed that the pattern of interaction in Subakof Pembaket Awen Selatan is categorized into two, namely the associative patterns (cooperation, help, and accommodation) and dissociative patterns (contravenes and conflicts). The communication pattern in Subak Pembaket Awen Selatan was heterophilic that is, the communication that occurs between different beliefs and backgrounds. The interaction model explains the limits of values and beliefs shared by each religion. These limits are activities that may and should not be done when Hindu and non-Hindu members interact and perform the six tasks and functions of subak.

Keywords: interaction pattern, social contact, social communication

\section{Pendahuluan}

\subsection{Latar Belakang}

Subak merupakan suatu masyarakat hukum adat yang memiliki karakteristik sosio-agraris-religius, yang merupakan perkumpulan petani yang mengelola air irigasi di lahan sawah (Windia, 2006). Pada umumnya anggota Subak di Bali, beranggotakan petani yang beragama Hindu, sehingga dalam kesehariannya sistem subak menjalankan ajaran Agama Hindu untuk menjalani kegiatan atau aktivitas di Subak.Namun, pada kenyataannya penduduk pulau Bali bukan hanya menganut Agama Hindu. Hal tersebut juga berpengaruh terhadap anggota subak yang ada di 
Bali. Beberapa subak di Bali ada yang beranggotakan non Hindu serta campuran antara Hindu dengan non Hindu (Pitana, 1997). Salah satu subak yang memiliki anggota petani non Hindu adalah Subak Pemaket Awen Selatan, Desa Pengambengan, Kecamatan Negara, Kabupaten Jembrana. Subak Pemaket Awen Selatan memiliki banyak anggota beragama non Hindu.Perbedaan agama yang dipeluk oleh anggota Subak Pamekat Awen Selatan menyebabkan timbul beragam potensi konflik. Konflik yang terjadi ini sangat berkaitan erat dengan fungsi organisasi Subak.Keenam fungsi organisasi subak dapat dicapai ababila terjadi interaksi sosial yang harmonis (Pitana, 1997). Interaksi sosial dalam jangka waktu yang lama akan membentuk suatu modal sosial. Adanya anggota Hindu dan non Hindu di Subak Pemaket Awen Selatan memicu potensi konflik dalam interaksi sosial dan modal sosial yang terjadi. Konflik tersebut, dapat antar individu, individu dengan kelompok, atau antar kelompok. Berdasarkan permasalahan di atas perlu adanya penelitian untuk mengetahui pola interaksi sosial anggota subak Hindu dan non Hindu di Subak Pemaket Awen Selatan Desa Pengambengan, Kecamatan Negara, Kabupaten Jembrana.

\subsection{Rumusan Masalah}

Berdasarkan uraian latar belakang maka dapat dirumuskan masalah sebagai berikut.

1. Bagaimanapola interaksi sosial antara anggota Subak yang beragama Hindu dan non Hindu di Subak Pemaket Awen Selatan di Desa Pengambengan, Kecamatan Negara, Kabupaten Jembrana?

2. Bagaimana pola komunikasi sosial antara anggota Subak yang beragama Hindu dan non Hindu di SubakPemaket Awen Selatan di Desa Pengambengan, Kecamatan Negara, Kabupaten Jembrana?

3. Bagaimana model pola intraksi sosial antara anggota Subak yang beragama Hindu dan non Hindu di Subak Pemaket Awen Selatan di Desa Pengambengan, Kecamatan Negara, Kabupaten Jembrana?

\subsection{Tujuan Penelitian}

Tujuan penelitian ini dilakukan untuk.

1. Menganalisis pola interaksi sosial antara anggota Subak yang beragama Hindu dan non Hindu di Subak Pemaket Awen Selatan di Desa Pengambengan, Kecamatan Negara, Kabupaten Jembrana.

2. Menganalisis pola komunikasi sosial antara anggota Subak yang beragama Hindu dan non Hindu di Subak Pemaket Awen Selatan di Desa Pengambengan, Kecamatan Negara, Kabupaten Jembrana.

3. Merancang model pola intraksi sosial antara anggota Subak yang beragama Hindu dan non Hindu di Subak Pemaket Awen Selatan di Desa Pengambengan, Kecamatan Negara, Kabupaten Jembrana. 


\section{Metode Penelitian}

\subsection{Lokasi dan Waktu Penelitian}

Penelitian ini dilaksanakan di Subak Pemaket Awen Selatan, Kecamatan Negara, Kabupaten Jembrana. Penelitian ini dilaksanakan dari bulan Januari sampai dengan bulan Maret 2017 mulai dari persiapan sampai penyusunan laporan penelitian. Pemilihan lokasi penelitian ini dilakukan dengan metode purposive yaitu metode penentuan lokasi penelitian yang dilakukan secara sengaja dengan pertimbangan sebagai berikut.

1. Subak Pemaket Awen Selatandi Desa Pengambengan adalah salah satu subak yang beranggotakan Hindu dan non Hindu.

2. Belum pernah dilakukan penelitian serupa di Subak Pemaket Awen Selatan, Desa Pengambengan, Kecamatan Negara, Kabupaten Jembrana.

\subsection{Sumber dan Jenis Data}

Sumber data dalam penelitian ini meliputi data primer dan data sekunder. Data primer adalah data yang langsung dikumpulkan oleh orang yang berkepentingan atau yang menggunakan data tersebut (Ibrahim, 2015). Data primer diperoleh dari hasil wawancara mendalam dengan informan kunci, menurut Ibrahim, (2015) data sekunder pada umumnya digunakan untuk memberikan gambaran tambahan, gambaran pelengkap atau diproses lebih lanjut Data sekunder penelitian ini yakni dokumen arsip (baik dari desa dan subak), buku-buku dan hasil penelitian sebelumnya (disertasi, tesis, dan skripsi) yang mampu memberikan gambaran mengenai keadaan seseorang atau masyarakat tempat kajian/penelitian.

Jenis data terdiri atas data kualitatif dan data kuantitatif. Data kualitatif, yaitu data yang berbentuk kata-kata atau yang berwujud pernyataan-pernyataan verbal, bukan dalam bentuk angka atau menguraikan paradigma, fenomena yang ada di lapangan secara alamiah dengan kata-kata atau gambar (Antara, 2004). Data kualitatif diperoleh melalui berbagai macam teknik pengumpulan data, seperti: wawancara, analisis dokumen, observasi yang telah dituangkan dalam catatan lapangan yang bersumber dari pekaseh, Kepala Desa, PPL (Petugas Penyuluh Lapangan), anggota petani beragama Hindu dan anggota petani beragama non Hindu di Subak Pemaket Awen Selatan. Data kuantitatif, yaitu data yang berupa angkaangka dan dapat dihitung dalam satuan tertentu. Data yang diperoleh dan dikumpulkan dalam penelitian inidipisahkan menurut jenisnya. Setelah dipisahkan maka selanjutnya diolah, dianalisis dan dijadikan dalam bentuk tabel-tabel frekuensi dan diberi penjelasan berdasarkan hasil kusioner dari responden (Antara, 2004). Data kuantitatif dalam penelitian ini seperti data jumlah subak dan luas subak.

\subsection{Penentuan Informan Kunci}

Pemilihan informandalam penelitian ini menggunakan teknik snowball sampling yaitu teknik pengambilan informan sumber data, yang pada awalnya jumlah sedikit, lama-lama menjadi besar. Pemilihan sempel dilakukan karena peneliti 
telah memahami bahwa informasi yang dibutuhkan dapat diperoleh dari suatu kelompok sasaran tertentu yang mampu memberikan informasi yang dikehendaki (Sugiyono, 2009). Penentuan informan dalampenelitian kualitatif berfungsi untuk mendapatkan informasi yang dapat menjawab tujuan penelitian, karena itu orang yang dijadikan sampel atau informan sebaiknya yang memenuhi kriteria sebagai berikut.

1. Pekaseh Subak Pemaket Awen Selatan.

2. Penyuluh pembangunan pertanian (PPL).

3. Anggota beragama Hindu Subak Pemaket Awen Selatan.

4. Anggota beragama non Hindu Subak Pemaket Awen Selatan.

\subsection{Metode Pengumpulan Data}

Metode pengumpulan data dalam penelitian ini melalui observasi, wawancara mendalam, dan dokumentasi. Wawancara dilakukan dengan tujuan untuk menggali informasi sesuai dengan rumusan masalah melalui informan kunci yang telah ditentukan, yaitu dengan mengajukan pertanyaan yang telah disusun sesuai dengan pedoman wawancara (Hasan, 2002). Wawancara menurut Lincon dan Guba (dalam Basrowi dan Suwandi, 2008) ialah mengonstruksi perihal orang, kejadian, kegiatan, organisasi, perasaan, motivasi, tuntutan, dan kepedulian, merekonstruksi kebulatankebulatan harapan pada masa yang akan datang, memverifikasi, mengubah, dan memperluas informasi dari orang lain. Observasi dilakukan untuk mengetahui keadaan langsung di Subak Pemaket Awen Selatan. Dokumentasi dapat berupa fotofoto keadaan wilayah penelitian dan pada saat kegiatan wawancara dengan informan kunci.

\subsection{Analisis Data}

Metode analisis yang digunakan dalam penelitian ini yaitu analisis deskriptif kualitatif. Metode deskriptif kualitatif adalah penggambaran secara kualitatif fakta, data, atau objek material yang bukan berupa rangkaian angka, melainkan berupa ungkapan bahasa atau wacana melalui interpretasi yang tepat dan sistematis (Wibowo, 2011).

\section{Hasil dan Pembahasan}

\subsection{Pola Interaksi Sosial antar Anggota Hindu dan Non Hindu}

Interaksi sosial yang terjadi di Subak Pemaket Awen Selatan dapat dikategorikan menjadi dua bagian sebagaimana yang disampaikan oleh sudarta yakni kontak sosial asosiatif dan disosiatif. Interaksi sosial tersebut dihubungkan dengan dengan enam fungsi subak yang diterapkan di Subak Pemaket Awen Selatan. Interaksi asosiatif dalam hubungannya dengan enam fungsi subak di Subak Pemaket Awen Selatan diwujudkan dengan melakukan kerjasama dan gotong dalam menjalankan enam fungsi subak yang terdiri dari kerjasama dan tolong menolong dalam pelaksanaan upacara keagamaan yakni pelaksanaan pengaci (syukuran) 
yangdiselenggarakan secara berbeda oleh anggota subak Hindu dan non Hindu, kerjasama dan gotong-royong dalam memelihara fasilitas subak, kerjasama dan gotong-royong dalam pengadopsian inovasi, kerjasama dan pemufakatan bersama dalan penyelesaian konflik dan kerjasama dalam pendistribusian air irigasi. Kontak sosial disosiatif dapat dilihat dari adanya persaingan dalam memperoleh air irigasi, adanya kontraversi yakni pertikaian yang tersembunyi diantara anggota subak dengan pekaseh, dan adanya konflik yang terjadi yang disebabkan kurangnya transparasi dalam pengelolaan dana bantuan subak.

\subsubsection{Interaksi asosiatif antar anggota Hindu dan non Hindu}

Pelaksanaan enam fungsi subak di Subak Pemaket Awen Selatan dilaksanakan dengan atas dasar hubungan atau kontak yang bersifat asosiatif yang diantaranya berupa sifat kerjasama antara Hindu dan non Hindu dalam upacara keagamaan dan pemeliharaan fasilitas subak, hubungan tolong menolong dalam keseharian antara umat Hindu dan non Hindu, akomodasi dalam penanganan konflik serta akulturasi dalam hal pengadopsian inovasi. Interaksi asosiatif merupakan komunikasi yang dilakukan dua orang atau lebih yang berdampak positif yang mengindikasikan adanya gerak mendekatkan atau menyatukan. Interaksi asosiatif tersebut dibagi tiga yaitu kerjasama, akomodasi, dan asimilasi (Sudarta, 2016). Hal tersebut juga terdapat di Subak Pemaket Awen Selatan terjadi interaksi yang bersifat asosiatif yang terjadi di antara anggota Hindu dan non Hindu di Subak Pemaket Awen Selatan.

\subsubsection{Interaksi disosiatifantar anggota Hindu dan non Hindu}

Interaksi disosiatif merupakan komunikasi yang dilakukan dua orang atau lebih yang menimbulkan hal yang negatif seperti persaingan, kontravensi, dan konflik (Sudarta, 2016). Kontraversi merupakan suatu bentuk proses sosial yang menunjukan ketidaksenangan atau ketidakpuasan terhadap pihak lain baik secara sembunyi atau terang-terangan(Soekanto, 2010). Subak Pemaket Awen Selatan terjadi interaksi yang bersifat disosiatif yang terjadi di antara Anggota Hindu dan non Hindu di Subak Pemaket Awen Selatan. Kontak sosial yang bersifat disosiatif yang terjadi antara anggota Hindu dan non Hindu di Subak Pemaket Awen Selatan terjadi dalam bentuk kontravensi dan konflik. Bentuk kontravensi yang terjadi antara anggota Hindu dengan non Hindu di subak ini adalah tidak ada transparansi dana PUAP sebesar Rp 100.000.000,00 kepada anggota subak lainnya yang menimbulkan ketidaksenangan atau ketidakpuasan terhadap pengurus subak. Bentuk konflik yang terjadi di subak ini adalah sikap acuh tak acuh anggota subak non Hindu terhadap awig-awig yang berlaku akibat dari kurang tegasnya pekaseh dalam menerapkan peraturan tersebut sehingga menimbulkan permasalahan bagi anggota Hindu dan memutuskan untuk berhenti dari keanggotaan subak. 


\subsection{Pola Komunikasiantar Anggota Hindu dan non Hindu}

Komunikasi Subak Pemaket Awen Selatan dilakukan oleh dua kebudayaan yang berbeda yakni antara Hindu dan non Hindu. Menurut Sudarta (2016) komunikasi yang terjadi diantara dua kebudayaan yang berbeda disebut dengan heterofoli dan komunikasi yang terjadi secara heterofoli dianggap kurang efektif. Pelaksanaan enam fungsi subak di Subak Pemaket Awen Selatan berdasarkan pada penelitian yang dilakukan terjadi kurang efektif dalam hal pelaksanaan kegiatan upacara keagamaan. Hal ini disebabkan karena adanya perbedaan nilai-nilai dan keyakinan yang dianut oleh anggota Hindu dan non Hindu sehingga sulit untuk memadukan kedua keyakinan tersebut dalam satu kegiatan keagamaan.

\subsection{Pola Model Interaksi Sosialantar Anggota Hindu dan non Hindu}

Model interaksi sosial yang terjadi di Subak Pemaket Awen Selatan dalam kaitannya dengan pelaksanaan enam tugas dan fungsi subak seperti yang dijelaskan dalam gambar (1) di bawah berupa hubungan yang saling ketergantungan serta saling mendukung antara anggota Hindu dan non Hindu. Hubungan tersebut dapat berupa hubungan antara individu dengan individu, hubungan individu dengan kelompok dan hubungan kelompok dengan kelompok dalam pelaksanaan enam tugas dan fungsi yang yang diantaranya berupa pencarian dan pendistribusian air irigasi, pengoperasian dan pemeliharaan fasilitas subak, penanganan konflik, kegiatan upacara keagamaan, pengerahan sumber daya,serta pengadopsian inovasi. Khusus untuk pelaksanaan tugas dan fungsi subak tentang pelaksanaan kegiatan upacara keagamaan, anggota Hindu dan non Hindu di Subak Pemaket Awen Selatan dibatasi oleh nilai-nilai dan keyakinan yang terkandung di masing-masing agama sehingga interaksi ini berbeda jika dibandingkan dengan interaksi dalam pelaksannan kelimatugas dan fungsi subak lainnya.

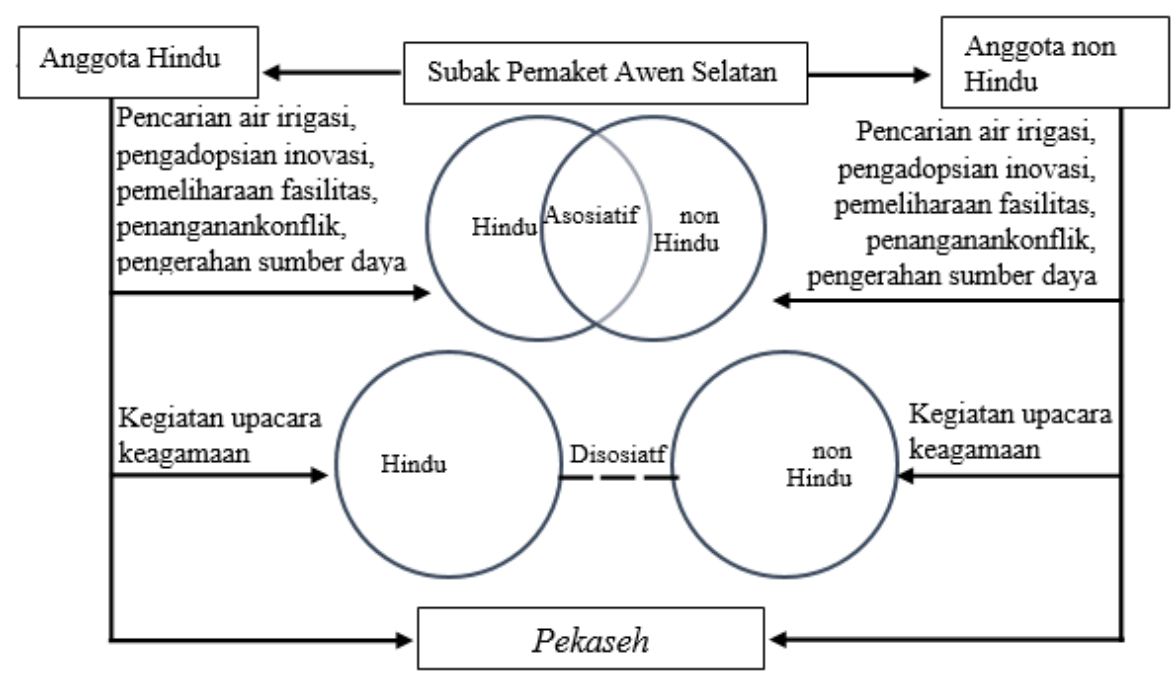

Gambar 1.

Model Interaksi Sosial Anggota Subak Pemaket Awen Selatan 


\subsubsection{Model Interaksi Individu Hindu dan non Hindu}

Hubungan atau interaksi yang terjadi di Subak Pemaket Awen Selatan tidak hanya terjadi secara kolektif antara Hindu dan non Hindu namun juga terdapat hubungan antara individu baik itu individu Hindu yang berinteraksi dengan individu non Hindu demikian juga sebaliknya. Hubungan tersebut diwujudkan dalam kaitannya dengan enam tugas dan fungsi subak yang menyangkut interaksi seharihari antara individu tersebut. Wujud dari interaksi individu dengan individu antara lain hubungan tolong menolong secara individu semisal individu yang beragama Hindu membantu menanggulangi hama penyakit yang menyerang padi anggota non Hindu.

Lebih lanjut, hubungan individu dengan individu di Subak Pemaket Awen Selatan diwujudkan dalam sikap saling menghormati antar keyakinan. Hal tersebut dibuktikan dengan tidak adanya diskriminasi rasial yang dialami oleh individu dalam kegiatan sehari-hari mereka. Hubungan-hubungan sosial tersebut murni didasari oleh adanya saling ketergantungan yang mengharuskan individu-individu tersebut saling hormat-menghormati maupun saling tolong-menolong.

\subsubsection{Model interaksi individu dengan kelompok anggota Hindu dan non Hindu}

Interaksi individu dengan kelompok di Subak Pemaket Awen Selatan terjadi melalui kontak-kontak sosial yang bersifat asosiatif dalam bentuk kerja sama yang diwujudkan dengan kegiatan-kegiatan baik itu kegiatan keagamaan maupun kegiatan sosial lainnya. Individu berpartisipasi dalam kegiatan-kegiatan yang dilakukan oleh kelompok. Contoh interaksi individu dengan kelompok adalah pada saat ada kegiatan upacara keagamaan baik itu di kelompok non Hindu ataupun kelompok Hindu. Apabila kegaiatan tersebut dilakukan oleh kelompok non Hindu, maka individu Hindu akan turut serta berpartisipasi. Partisipasi tersebut murni sebagai hubungan sosial individu Hindu dengan kelompok non Hindu dan biasanya diwujudkan dalam bentuk undangan pribadi dalam sebuah kegiatan yang diselenggarakan.

\subsubsection{Model interaksi kelompok Hindu dan non Hindu}

Interaksi kelompok dengan kelompok di Subak Pemaket Awen Selatan terjadi antara kelompok Hindu dengan kelompok non Hindu. Dalam hubungan ini, kedua kelompok tersebut membangun sebuah hubungan yang bersifat saling menguntungkan. Interaksi tersebut kemudian diwujudkan dalam kegiatan-kegiatan gotong-royong yang sifatnya kolektif untuk kepentingan bersama dalam wadah Subak Pemaket Awen Selatan. Hubungan kelompok Hindu dan non Hindu di Subak Pemaket Awen Selatan mencakup pada hubungan sosial yang meliputi hampir seluruh aspek kehidupan. Seperti pada contohnya adalah pada saat kegiatan upacara agama yang diselenggarakan oleh umat Hindu, anggota non Hindu dalam kapasitasnya sebagai kelompok ikut serta dalam kegiatan tersebut. Kelompok non 
Hindu ini biasanya merupakan kelompok pengajian yang anggotanya juga merupakan anggota Subak Pemaket Awen Selatan.

\section{Simpulan dan Saran}

\subsection{Simpulan}

Berdasarkan hasil dari penelitian di atas yang telah dijelaskan dan dipaparkan sesuai dengan rumusan masalah yang telah ditentukan maka dapat disimpulkan beberapa hal pokok sebagai berikut.

\section{Pola interaksi kontak sosial}

Interaksi dalam bentuk asosiatif anggota Hindu dan Non Hindu di Subak Pemaket Awen Selatan antara lain, dalam bentuk kerjasama di wujudkan dalam bentuk tolong menolong, dalam kehidupan sehari-hari.Interaksi asosiatif kerjasama dalam bentuk gotong royong dilakukan untuk pemeliharaan fasilitas irigasi.Hubungan asosiatif akomodasi antara anggota dalam bentuk mediasi saat menyelesaikan permasalahan yang terjadi.Interaksi asosiatif akulturasi antara anggota Hindu dan non Hindu terkait dengan penyerapan inovasi baru dilakukan tanpa menghilangkan tradisi lama.

Interaksi dalam bentuk disosiatif anggota Hindu dan Non Hindu di Subak Pemaket Awen Selatan terdiri dari: interaksi disosiatif yaitu, dalam bentuk kontraversi terkait dengan kurangnya transparasi dalam pengelolaan keuangan subak.Interaksi disosiatif antara anggota dalam bentuk konflik karena kurang tegasnya pekaseh dalam menerapkan awig-awig subak.

2. Pola komunikasi sosial

Subak Pemaket Awen Selatan terdapat dua keyakinan yang berbeda yakni Hindu dan non Hindu sehingga komunikasi yang terjadi bersifat heterofoli. Dalam hal ini, perbedaan keyakinan tersebut tidak menjadi suatu permasalahan sepanjang masing-masing dari keyakinan tersebut saling menghormati dan memahami nilainilai dan keyakinan yang dianut oleh masing-masing anggota dalamn kehidupan sehari-hari meraka dalam melaksanakan enam tugas dan fungsi subak.

3. Pola model interaksi sosial

Model interaksi sosial yang terjadi di Subak Pemaket Awen Selatan dalam kaitannya dengan pelaksanaan enam tugas dan fungsi subak seperti yang dijelaskan dalam bagan diatas berupa hubungan yang saling ketergantungan serta saling mendukung antara anggota Hindu dan non Hindu. Hubungan tersebut dapat berupa hubungan antara individu dengan individu, hubungan individu dengan kelompok dan hubungan kelompok dengan kelompok dalam pelaksanaan enam tugas dan fungsi yang yang diantaranya berupa pencarian dan pendistribusian air irigasi, pengoperasian dan pemeliharaan fasilitas subak, penanganan konflik, kegiatan upacara keagamaan, serta pengadopsian inovasi.

Namun terdapat perbedaan interaksi sosial dalam pelaksanaan kegiatan upacara keagamaan, anggota Hindu dan non Hindu di Subak Pemaket Awen Selatan yakni adanya batasan nilai-nilai dan keyakinan yang dianut oleh masing-masing agama. 
Batasan tersebut berupa kegiatan-kegiatan yang boleh dan tidak boleh dilakukan ketika anggota Hindu dan non Hindu berinteraksi. Interaksi sosial yang berkaitan dengan pelaksanaan lima tugas dan fungsi subak pekaseh memiliki peran sentral dalam mengkoordinir dan menengahi hubungan-hubungan tersebut. Berhubungan dengan hal tersebutpekaseh memberikan pengarahan terkait dengan pelaksaan tugas dan fungsi subak serta pekaseh juga yang mengontrol dan menjadi pengambil keputusan terakhir dalam kegiatan anggota subak Hindu dan non Hindu tersebut dalam pelaksanaan enam tugas dan fungsi subak.

\subsection{Saran}

Bentuk interaksi yang terjadi di Subak Pemaket Awen Selatan adalah interaksi asosiatif, namun bukan berarti tidak ada ancaman untuk terjadi interaksi disosiatif. Kondisi tersebut perlu diantisipasi dengan tindakan-tindakan seperti yang di rekomendasikan di bawah ini.

1. Kepada pekaseh disarankan dalam pengelolaan keuangan lebih transparan kepada seluruh anggota Subak Pemaket Awen Selatan agar tidak menimbulkan kecurigaan yang dapat memicu konflik dikalangan anggota petani.

2. Kepada anggota Subak Pemaket Awen Selatan agar lebih sering duduk bersama, berinteraksi, dan melakukan rapat tiap awal musim tanam dan di akhir musim tanam agar nantinya dapat meningkatkan hubungan yang harmonis, meningkatkan toleransi, dan meningkatkan kerja sama serta gotong royong antar anggota baik Hindu dan Non Hindu.

\section{Ucapan Terimakasih}

Penulis mengucapkan terimakasih kepada semua pihak yang telah membantu dalam menyelesaikan naskah jurnal ini sampai di terbitkan di e-jurnal.

\section{Daftar Pustaka}

Antara, Made. 2014. Format dan Subtansi Proposal Penelitian: Bahan Kuliah Metode Penelitian Sosial Ekonomi. Denpasar: Program Studi Agribisnis Fakultas Pertanian Universitas Udayana.

Basrowi dan Suwandi. 2008. Memahami Metode Kualitatif. Jakarta: Rineka Cipta

Hasan. 2002. Pokok-pokok Materi Metodelogi Penelitian dan Aplikasinya. Jakarta: Ghalia Indonesia.

Ibrahim, M. A. 2015. Metodelogi Penelitian Kualitatif. Bandung: Alfabeta.

Pitana, I G. 1997. Subak, Sistem Irigasi Tradisional di Bali (Sebuah Canangsari). Denpasar: Upada Sastra.

Soekanto, Soerjono. 2010. Sosiologi Suatu Pengantar. Jakarta: Raja Grafindo Persada.

Sudarta, Wayan. 2016. Sosiologi Pertanian. Denpasar: Udayana University Press.

Sugiyono. 2009. Metode Penelitian Kuantitatif, Kualitatif dan R\&D. Bandung: Alfabeta.

Wibowo. 2011. Manajemen Kinerja. Jakarta: Raja Grafindo Persada. 
Windia, Wayan. 2006. Transformasi Sistem Irigasi Subak yang Berlandaskan Konsep Tri Hita Karana. Denpasar: Pustaka Bali Post. 